\title{
Is physical training contraindicated in patients with deep vein thrombosis during cardiac rehabilitation?
}

\section{Il training fisico è controindicato nei pazienti con trombosi venosa profonda durante riabilitazione?}

\author{
Marco Ambrosetti, Mario Salerno, Walter Ageno ${ }^{\circ}$, Roberto Tramarin, Roberto FE Pedretti
}

\begin{abstract}
Is physical training contraindicated in patients with deep vein thrombosis during cardiac rehabilitation? $M$. Ambrosetti, M. Salerno, W. Ageno, R. Tramarin, RFE Pedretti.

Deep vein thrombosis is a potential complication in patients admitted to cardiac rehabilitation programs after acute coronary syndromes, episodes of acute congestive heart failure, and cardiac revascularization. A common clinical problem in these patients is to decide whether to start or continue physical train-
\end{abstract}

\begin{abstract}
ing or not, given the risk of pulmonary embolism. Until definite evidence becomes available, careful patient selection and inpatient supervision may avoid the a priori withdrawal of such an important core component of cardiac rehabilitation programs.

Keywords: deep vein thombosis, cardiac rehabilitation, physical training.
\end{abstract}

Monaldi Arch Chest Dis 2005; 64: 24-26.

Division of Cardiology, IRCCS Fondazione Salvatore Maugeri, Tradate, Italy.

${ }^{\circ}$ Department of Internal Medicine, University of Insubria, Varese, Italy.

Corresponding author: Dr Marco Ambrosetti; Division of Cardiology; IRCCS Fondazione Salvatore Maugeri; Via Roncaccio 16, I-21049Tradate (VA), Italy; E-mail address: mambrosetti@fsm.it

There is convincing evidence that structured programs of cardiac rehabilitation (CR) favourably improve the clinical course of cardiovascular diseases, and their provision is now considered a standard of care for patients suffering from a variety of chronic and post-acute conditions. CR is currently indicated for all patients with a diagnosis of acute myocardial infarction (MI), patients who have undergone coronary artery bypass graft surgery $(\mathrm{CABG})$, percutaneous transluminal coronary angioplasty (PTCA) or cardiac transplantation, patients with chronic stable angina, chronic heart failure (CHF), intermittent claudication (IC), and subjects at high risk for cardiovascular disease. ${ }^{1}$

Several of these conditions are significantly associated with an increased risk of venous thromboembolism (VTE). Data from a large registry of United States patients ${ }^{2}$ show that diagnosis of deep vein thrombosis (DVT) is common in inpatients with cardiovascular disease, and is even more common than in inpatients with neurologic disease or inpatients with cancer. The overall estimated incidence of DVT after MI is $24 \%$, although the increasing use of combined antithrombotic therapies such as thrombolytics and heparins in these patients might have progressively reduced such rates. ${ }^{3} \mathrm{CHF}$ also predisposes to VTE with a reported incidence of approximately $20 \%$ in the absence of antithrombotic prophylaxis during hospitalization for acute decompensation (3). Among surgical conditions, ap- proximately $20 \%$ of patients undergoing CABG develope DVT before discharge. 4

\section{The clinical problem}

Physical training (PT) has a pivotal role among the core components of CR programs and several clinical trials have been published indicating the safety and efficacy of PT in stable coronary artery disease (CAD), CHF, and IC.6-8 Walking, cycling, and calisthenics are widely applied as the modality of exercise, and intensities of $60-80 \%$ heart rate reserve and 60 $80 \%$ of the predetermined peak heart rate are often prescribed. In addition, musculoskeletal flexibility and movement coordination are encouraged. In the case of concomitant DVT, these modalities of exercise have the potential to both worsen DVT symptoms and increase the risk of subsequent pulmonary embolism (PE). Because of venous obstruction and reflux, outflow cannot match inflow under conditions of increased muscle blood flow during exercise, thus promoting fluid transudation from the capillaries into the interstitial space and impairing leg muscle perfusion. As a consequence, patients may experience exerciseinduced leg swelling and muscle fatigue. Exercise can also theoretically cause the breakup of a proximal clot and thus the embolization to the lungs. This is generally the leading reason for stopping PT in patients with concomitant DVT. In 1992 the Task Force of the Working Group on Cardiac Rehabilitation of the Eu- 
ropean Society of Cardiology included the presence of "active or recent thrombophlebitis" among absolute contraindications to prescription of PT in patients with CAD, CHF, and cardiac surgery. ${ }^{9}$ In 2001, the Working Group on Cardiac Rehabilitation \& Exercise Physiology and Working Group on Heart Failure of the European Society of Cardiology listed "thrombophlebitis" among absolute contraindications to PT in patients with stable CHF.7

However, we believe that there is still inadequate evidence to support these recommendations and that the need to categorically avoid or stop PT in all DVT patients irrespective of clinical symptoms severity, clots localization and morphology, response to antithrombotic therapy, cardiopulmonary status, patient compliance, and any other variable related to the individual risk of VTE is debatable.

\section{Challenges in considering physical exercise in observations DVT}

In our opinion, several observations give plausibility to the hypothesis that in selected patients with DVT PT may be safely continued. Indeed, it is possible to hypothesize that: 1) exercise could ameliorate DVT symptoms by increasing the calf muscle pump, reducing the hydrostatic pressure gradient required for edema formation; 2) exercise could reduce venous stasis and consequently prevent recurrent or progressive thrombosis; and 3) several mechanisms involved in the documented beneficial effect of PT in patients with IC (such as redistribution of blood flow, changes in blood rheology, metabolic changes, changes in skeletal muscle morphology, and changes in pain perception) could also be favourable for patients with DVT. In the recent past, DVT patients were commonly placed at bed rest for up to ten days after diagnosis; more recently, clinical practice has shifted towards earlier ambulation. Although strong evidence to support this strategy is still lacking, a large proportion of opinion leaders in the field of VTE believe that early ambulation leads to a more rapid resolution of DVT symptoms and is sufficiently safe once appropriate antithrombotic therapy has been started.

\section{Strategies and evidence}

A recent review by Aldrich and Hunt 10 identified only 3 controlled clinical trials ${ }^{11-13}$ and 1 large prospective uncontrolled study 14 that focused on the issue of early ambulation after DVT (table 1). There were no significant differences concerning the occurrence of PE in early ambulating patients compared with the bed rest groups. All studies suggested that, after careful evaluation, DVT patients can ambulate early in the absence of an increased risk of PE. Although not specified, it is also reasonable to assume that clinical studies evaluating the outpatient management of DVT with low molecular weight heparin (LMWH) included early ambulation, or at least did not promote bed rest at home. Given the safety of LMWH administered at home, 15 we can argue that ambulation was correspondingly safe.

However, early ambulation and compression therapy cannot be considered as structured PT activities. We sought evidence from the medical literature to identify studies addressing the efficacy and safety of PT in the acute management of DVT patients, especially in the cardiovascular setting. A series of MEDLINE database searches were performed using the following Medical Subject headings: deep vein thrombosis, pulmonary embolism, venous thromboembolism, exercise, physical training, and cardiac rehabilitation. This strategy yielded no study that we considered relevant to answer the above question. We only found one article by Kahn et al 16 in which treadmill exercise was shown not to worsen post-thrombotic symptoms, although no convincing evidence was found regarding the adoption of PT immediately after diagnosis of DVT.

At the institute of Tradate of the Salvatore Maugeri Foundation, we performed two clinical studies evaluating the postoperative incidence of DVT in an unselected ${ }^{17}$ and a selected 18 population of CABG patients entering CR. Overall, 67 (18\%) had DVT. Proximal and isolated distal DVT cases were respectively $13 \%$ ( 9 cases) and $87 \%$ (58 cases) of the whole DVT population. Forty-three DVT cases $(64 \%)$ were diagnosed at admission, while 4 cases $(6 \%)$ were diagnosed after a structured PT program was started.

Table 1. - Studies evaluating early mobilization in patients with deep venous thrombosis (DVT)

\begin{tabular}{|c|c|c|c|}
\hline Author, year & Patients evaluated & Strategy after diagnosis of DVT & Development of PE \\
\hline \multirow[t]{2}{*}{ Aschwenden ${ }^{11}, 2001$} & 69 & LMWH, early ambulation $>4 \mathrm{~h} / \mathrm{d}$, and ES & $14 \%$ \\
\hline & 60 & LMWH and immobilization for $4 \mathrm{~d}$ & $10 \%$ \\
\hline \multirow[t]{2}{*}{ Schellong12, 1999} & 63 & LMWH/OA, early ambulation, and ES & $22 \%$ \\
\hline & 59 & LMWH/OA, immobilization for 8d, and ES & $17 \%$ \\
\hline \multirow[t]{3}{*}{ Partsch $^{13}, 2000$} & 15 & LMWH, early ambulation & $13 \%$ \\
\hline & 15 & LMWH, early ambulation, and ES & $7 \%$ \\
\hline & 15 & LMWH and immobilization & $7 \%$ \\
\hline Partsch $^{14}, 2001$ & 1,289 & LMWH/OA, early ambulation, and ES & $\begin{array}{l}14 \% \text { in proximal DVT, } \\
3 \% \text { in isolated distal DVT }\end{array}$ \\
\hline
\end{tabular}


These findings indicate that DVT may frequently occur in $\mathrm{CABG}$ patients during $\mathrm{CR}$ and most often is confined to the calf veins. In the case of DVT diagnosed during CR, our policy attributes to the treating physician the decision to initiate/continue or to stop the PT program after careful patient evaluation. The key elements providing an objective basis for the clinical decision are medical history, assessment of cardiopulmonary status, clots localization, ultrasonographic surveillance, and initiation of appropriate anticoagulation therapy. In the case of a decision favouring PT, patients with distal isolated DVT receive exercise training with an optimal intensity of $80 \%$ of peak VO2 (or peak heart rate) as detected by treadmill exercise stress test, while patients with proximal DVT receive low workload exercise (12 Borg Scale) in the absence of cardiac stress testing. The standard duration of the program is at least 3 weeks. For the purpose of this review, we analysed the safety of such a policy in terms of the occurrence of clinically evident PE among patients enrolled in the two studies. Of $67 \mathrm{pa}-$ tients considered, 2 (3\%) did not have PT prescribed because of concomitant acute congestive heart failure ( 1 case) and an absolute contraindication to antithrombotic therapy (1 case). The incidence of PE at 1 month in DVT patients in whom PT was not contraindicated was 3\% (2 cases). Both PE cases occurred within day 2 after diagnosis of DVT. In one case a single low workload PT session was administered after prescription of anticoagulants and elastic stockings.

\section{Conclusions}

Recent challenges in the treatment of DVT and limited experiences suggest the hypothesis that DVT may not represent an absolute contraindication to some degree of PT activity during the inpatient phase of CR. In this perspective, the evaluation of the individual patient profile and the use of PT like a drug per se are crucial to ensure a safe management. In our opinion, the absence of respiratory symptoms, a stable clot, and the institution of appropriate anticoagulation may favour the decision to start or to continue PT after diagnosis of DVT. However, such a decision needs to be tailored to clinical circumstances, available facilities, and local expertise. Controlled trials of structured PT in patients with acute DVT are warranted to provide definite recommendations.

\section{Riassunto}

La trombosi venosa profonda può complicare il decorso riabilitativo di pazienti con esiti di sindrome coronarica acuta, scompenso cardiaco e rivascolarizzazione coronarica. In questi casi la decisione circa l'opportunità di iniziare o proseguire il previsto programma di training fisico può essere problematica, stante il potenziale rischio di embolizzazione dei trombi periferici a livello del circolo polmonare. Sebbene corpose evidenze non siano al momento disponibili, l'appropriata selezione dei pazienti e l'attenta supervisione clinica potrebbero evitare l'aprioristica rinuncia a uno dei principali componenti dei programmi di riabilitazione cardiologica.

Parole chiave: trombosi venosa profonda, riabilitazione cardiologia, training fisico.

\section{References}

1. Giannuzzi P, Saner H, Bjornstad H, et al. Secondary prevention through cardiac rehabilitation. Position paper of the working group on cardiac rehabilitation and exercise physiology of the European Society of Cardiology. Eur Heart J 2003; 24: 1273-1278.

2. Goldhaber SZ, Tapson VF. A prospective registry of 5,451 patients with ultrasound-confirmed deep vein thrombosis. Am J Cardiol 2004; 93: 259-262.

3. Geerts WH, Heit JA, Clagett GP, et al. Prevention of venous thromboembolism. Chest 2001; 119 (suppl 1): 132S-175S.

4. Goldhaber SZ, Hirsch DR, MacDougall RC, et al. Prevention of venous thrombosis after coronary artery bypass surgery (a randomized trial comparing two mechanical prophylaxis strategies). Am J Cardiol 1995; 76: $993-$ 996.

5. Prandoni P, Bilora F, Marchiori A, et al. An association between atherosclerosis and venous thrombosis. $N$ Engl $J$ Med 2003; 348: 1435-1441.

6. Joliffe JA, Rees K, Taylor RS, et al. Exercise-based rehabilitation for coronary heart disease. The Cochrane Library, Volume (Issue 3) 2001.

7. Working group on cardiac rehabilitation \& exercise physiology and working group on heart failure of the European Society of Cardiology. Recommendations for exercise training in chronic heart failure patients. Eur Heart $J$ 2001; 22: 125-135.

8. Gardner AW, Poehlman ET. Exercise rehabilitation programs for the treatment of claudication pain. JAMA 1995; 274: 975-980.

9. Recommendations by the Working Group on Cardiac Rehabilitation of the European Society of Cardiology. Longterm comprehensive care of cardiac patients. Eur Heart J 1992; 13 (suppl C): 1C-45C.

10. Aldrich D, Hunt DP. When can the patient with deep venous thrombosis begin to ambulate? Phys Ther 2004; 84: 268-273.

11. Aschwanden M, Labs KH, Engel H, et al. Acute deep vein thrombosis: early mobilization does not increase the frequency of pulmonary embolism. Thromb Haemost 2001: 85: 42-46.

12. Schellong SM, Schwarz T, Kropp J, Prescher Y, Beuthien-Baumann B, Daniel WG. Bed rest in deep vein thrombosis and the incidence of scintigraphic pulmonary embolism. Thromb Haemost 1999; 82 (suppl 1): 127-129.

13. Partsch H, Blattler W. Compression and walking versus bed rest in the treatment of proximal deep venous thrombosis with low molecular weight heparin. J Vasc Surg 2000; 32: 861-869.

14. Partsch H. Therapy of deep vein thrombosis with low molecular weight heparin, leg compression and immediate ambulation. Vasa 2001; 30: 195-204.

15. Levine MN, Gent M, Hirsh J, et al. A comparison of lowmolecular-weight heparin administered primarily at home with unfractionated heparin administered in the hospital for proximal deep-vein thrombosis. N Engl J Med 1996; 334: 677-681.

16. Kahn SR, Azoulay L, Hirsch A, Haber M, Strulovitch C, Shrier I. Acute effects of exercise in patients with previous deep venous thrombosis. Impact of the postthrombotic syndrome. Chest 2003; 123: 399-405.

17. Ambrosetti M, Salerno M, Zambelli M, Mastropasqua F, Tramarin R, Pedretti RFE. Deep vein thrombosis among patients entering cardiac rehabilitation after coronary artery bypass surgery. Chest 2004; 125: 191-196.

18. Ambrosetti M, Salerno M, Pedretti RFE. TVP dopo BPAC: Resa di una policy operativa di screening validata su base osservazionale. It Heart J 2003; 4 (suppl 1): 25S (abstract). 